\title{
Strategy for nuclear-magnetic-resonance-based metabolomics of human feces
}

\author{
Lamichhane, Santosh; Yde, Christian Clement; Schmedes, Mette Søndergaard; Max Jensen, Henrik; \\ Meier, Sebastian; Bertram, Hanne Christine
}

\author{
Published in: \\ Analytical Chemistry
}

Link to article, DOI:

10.1021/acs.analchem.5b00977

Publication date:

2015

Document Version

Peer reviewed version

Link back to DTU Orbit

Citation $(A P A)$ :

Lamichhane, S., Yde, C. C., Schmedes, M. S., Max Jensen, H., Meier, S., \& Bertram, H. C. (2015). Strategy for nuclear-magnetic-resonance-based metabolomics of human feces. Analytical Chemistry, 87(12), 5930-5937. https://doi.org/10.1021/acs.analchem.5b00977

\section{General rights}

Copyright and moral rights for the publications made accessible in the public portal are retained by the authors and/or other copyright owners and it is a condition of accessing publications that users recognise and abide by the legal requirements associated with these rights.

- Users may download and print one copy of any publication from the public portal for the purpose of private study or research.

- You may not further distribute the material or use it for any profit-making activity or commercial gain

- You may freely distribute the URL identifying the publication in the public portal 


\section{Strategy for nuclear-magnetic-resonance-based metabolomics of human feces}

Santosh Lamichhane ${ }^{1}$, Christian C. Yde ${ }^{1}$, Mette Søndergård Schmedes ${ }^{1}$, Henrik Max Jensen ${ }^{2}$, Sebastian Meier $^{3}$, and Hanne Christine Bertram ${ }^{1 *}$

${ }^{1}$ Department of Food Science, Aarhus University, Kirstinebjergvej 10, DK-5792 Aarslev, Denmark.

${ }^{2}$ DuPont Nutrition Biosciences ApS, Edwin Rahrsvej 38, 8220 Brabrand, Aarhus, Denmark

${ }^{3}$ Technical University of Denmark, Department of Chemistry, Kemitorvet, Building 201, DK2800 Kgs. Lyngby, Denmark

* Corresponding author. Email: hannec.bertram@food.au.dk 


\section{Abstract:}

2 Metabolomic analyses of fecal material are gaining increasing attention because the gut microbial 3 ecology and activity have an impact on the human phenotype and regulate host metabolism. Sample 4 preparation is a crucial step, and in this study we recommend a methodology for extraction and 5 analysis of fresh feces by NMR-based metabolomics. The evaluation of extraction solvents showed 6 that buffer extraction is a suitable approach to extract metabolic information in feces. So, the effects 7 of weight-to-buffer ( $\mathrm{Wf:} \mathrm{Vb})$ combinations and the effect of sonication and freeze-thaw cycles on 8 the reproducibility, chemical shift variability, and signal to noise ratio (SNR) of the ${ }^{1} \mathrm{H}$ NMR 9 spectra were evaluated. Based on our results, we suggest that fresh fecal extraction with a Wf: $\mathrm{Vb}$ ratio of 1:2 may be the optimum choice to determine the overall metabolite composition of feces. In

11 fact, more than 60 metabolites have been assigned in the NMR spectra obtained from the fresh fecal 12 buffer extract, and assignments of the lipophilic signals are also presented. To our knowledge, some 13 of the metabolites are reported here for the very first time employing ${ }^{1} \mathrm{H}$ NMR spectroscopy on human fecal extracts.

Keywords: Nuclear magnetic resonance, metabolomics, gut, human feces, metabolites 


\section{Introduction}

Metabolomics is a holistic approach to study systematic metabolic changes in biological samples. In general, nuclear magnetic resonance (NMR) and mass spectrometry (MS) are the analytical techniques used to observe and quantify metabolites from biological samples, and each technique has its own advantages and disadvantages. NMR-based metabolomics has emerged as a reliable high throughput analytical technique that has been extensively applied to a variety of biological samples such as urine, plasma, tissues, saliva, milk, seminal fluid, and sputum. ${ }^{1-4}$ Presently, urine and plasma are the most common sample types included in metabolomics studies. However, metabolomics on fecal material is gaining increased attention because gut ecology has an impact on the human phenotype and gut-microbe cross talk is regarded as one of the key determinants in the regulation of host metabolism. ${ }^{5-11}$ Because feces comes into direct contact with the colon and sample collection is non-invasive, feces is the most biologically most relevant sample material for metabolomics studies aiming to explore gut microbial activity and thereby gut health status. To date, NMR studies focused on fecal metabolomics have been applied to gain insight into metabolic effects involved in dietary interventions ${ }^{12,13}$ and to study gut diseases such as inflammatory bowel disease, ${ }^{14,15}$ ulcerative colitis, ${ }^{14}$ and colorectal cancer. ${ }^{16}$ An increased understanding of the metabolic activity in the colon may contribute to the identification of new biomarkers that could be related to health or disease status and molecular regulation of the complex gut system.

In order to extract as much information as possible from a complex fecal sample, optimization and standardization of an analytical methodology are essential. Although several studies have been reported on fecal metabolomics, ${ }^{12,14-16}$ few studies have focused on optimizing the NMR methodology for fecal extracts and detailed spectral assignments have rarely been reported. ${ }^{17-19}$ Two of the most important factors to consider in the optimization of an extraction method are (i) the 
production of reproducible NMR spectra with low inter-sample chemical shift variability and (ii) high signal-to-noise ratio (SNR). In addition, the extraction method should preferably be rapid, robust, (and suitable) and compatible with high-throughput analyses. Previously, fecal sample extractions have been performed by centrifugation, ${ }^{20} \mathrm{D}_{2} \mathrm{O},{ }^{21}$ distilled water, ${ }^{16}$ buffers, ${ }^{14,22}$ and mixed solvent extractions on lyophilized samples. ${ }^{18}$ Lyophilization is advantageous, as it minimizes the effect of solvent dilution (water content) on the feces. However, lyophilization affects the concentration of volatile metabolites, such as short chain fatty acids and succinate. ${ }^{18,19}$ Therefore, to reduce the loss of volatile metabolites and minimize the steps required during extraction; fresh fecal samples are considered the preferred choice for fecal metabolomics studies. Buffer extraction might be the most suitable approach to extract metabolic information as it reduces inter-sample $\mathrm{pH}$ variation during extraction. In order to obtain reproducible NMR spectra with lower inter-sample chemical shift variability and high SNR, the choice of extraction solvents must be evaluate and the fecal weight-to-buffer volume (Wf:Vb) must therefore be optimized.

In previous studies, different extraction solvents were implied for extraction ${ }^{16,18-20}$ and $\mathrm{Wf:Vb}$ ratios of $1: 50,{ }^{14} 1: 5^{16}, 1: 10,{ }^{23} 1: 2$ and an unknown ratio ${ }^{15,17,22}$ have been applied, but none of the studies report the rationale for their choice of solvent and the weight-to-buffer volume. Wu et al. ${ }^{24}$ have recommended the use of a $\mathrm{Wf:} \mathrm{Vb}$ ratio of $1: 10$ and the pooling of the first two extracts. It is also noteworthy that the recommendation (Wf: $\mathrm{Vb}$ of $1: 10$ ) was solely based on evaluation of chemical shift inconsistency and the experiment was conducted in fecal material from mice. Saric et al. showed that the fecal metabolome varies between species and, more specifically, the human metabolome contained lower levels of lactate and amino acids compared to mice and rats. ${ }^{19}$ Thereby, this finding urges further investigation of the choice of fecal weight-to-buffer ratio to extract metabolites from fresh human feces in metabolomic analyses. Besides that, the fecal 
metabolomics studies have focused on the analysis of intracellular bacterial metabolites; therefore,

67 different sample pretreatment techniques have been used to homogenize fecal samples. However,

68 the presence of different residual food components in the feces might affect the extraction.

69 Therefore, it is of interest to compare the effects of sample pre-treatment and the choice of weight-

70 to-buffer ratio during metabolic profiling from fresh human samples. In the present study we aimed

71 to compare the effect of different solvents during extraction, weight-to-buffer combinations on the 72 reproducibility, chemical shift variability, overall metabolite composition and SNR of the NMR

73 spectra from healthy human feces. In addition, we analyzed the consistency of fecal metabolite 74 composition upon different sample treatment techniques (sonication and freeze-thaw cycles) and 75 suggest an optimized protocol for NMR-based metabolomics analyses of human feces. 


\section{Sampling and sample material}

Fecal material from nine healthy volunteers was used for the study. The study protocol was approved by the Ethics and Research Committee and conducted according to the guidelines in the Declaration of Helsinki. The fecal material was collected from all subjects in a falcon tube immediately after defecation. The samples were then stored at $-20{ }^{\circ} \mathrm{C}$ prior to analysis. Initially, fecal samples from four healthy volunteers were used to optimize the fecal-to-water buffer ratio during extraction. Samples from an additional five subjects were included to elucidate the reproducibility of the method and the stability over time.

\section{Fecal metabolite extraction}

Fecal water was extracted to ratios of 1:2, 1:5, and 1:10 (weight of fresh feces-to-buffer) in $0.75 \mathrm{M}$ phosphate buffered saline (PBS, pH 7.4). The samples were homogenized by whirl mixing for 2 min, and then aliquots were centrifuged at $10,000 \mathrm{~g}$ for 15 minutes at $4{ }^{\circ} \mathrm{C}$ (Eppendorf 5471 , USA). The supernatants were carefully removed and stored in Eppendorf tubes at $-80{ }^{\circ} \mathrm{C}$ until analysis. To determine recovery, feces from one individual $(\mathrm{n}=3)$ was spiked with $100 \mu \mathrm{L}$ of standards maleic acid, dimethyl sulfone, and succinic acid $(0.05 \mathrm{M})$. Fecal water was extracted to ratios of 1:2, 1:5, and 1:10 (w/v) as described earlier. The recovery values of dimethyl sulfone, and succinic acid were referenced to maleic acid. In addition, to investigate the influence of solvent during fecal metabolites extraction, feces from one individual has been extracted in duplicate with distilled water, $\mathrm{D}_{2} \mathrm{O}$ extraction, (adapted from Monleón et al. ${ }^{16}$ ) and using combination of methanol/chloroform/water (section A, supplementary information). 


\section{Freeze thaw and sonication treatment}

To compare the effect of sample pretreatment on the fecal NMR profile; we extracted feces simultaneously with/without freeze-thaw and sonication treatment. During freeze thaw whirl-mixed samples were frozen to $-18{ }^{\circ} \mathrm{C}$ for 10 minutes and immediately thawed at $4{ }^{\circ} \mathrm{C}$ for $10 \mathrm{~min}$ in Eppendorf tubes (Eppendorf 5471, USA). This treatment was replicated for 3 cycles. Sonication was conducted between each freeze thaw cycle (Branson 5210, USA). The samples were placed in Eppendorf tubes and sonicated for three consecutive cycles of 2 min on and off between each freeze thaw cycle.

\section{pH measurement}

The $\mathrm{pH}$ values of the fecal extracts diluted to $1: 2,1: 5$, and 1:10 (w/v) in $0.75 \mathrm{M}$ phosphate buffered saline (PBS, $\mathrm{pH} 7.4)$ were measured at room temperature $\left(22^{\circ} \mathrm{C}\right)$ before $\mathrm{NMR}$ analysis, using $\mathrm{pH}$ electrodes for NMR sample tubes (IKATRON®, Germany).

\section{${ }^{1}$ H NMR spectroscopic analyses}

Fecal water samples extracted in PBS were thawed and centrifuged at 10,000 $g$ for 15 minutes at $4^{\circ} \mathrm{C}$ (Eppendorf 5471, USA). A volume of $500 \mu \mathrm{L}$ of clear supernatant was transferred to a $5 \mathrm{~mm}$ NMR tube, and $100 \mu \mathrm{L}$ of deuterium oxide $\left(\mathrm{D}_{2} \mathrm{O}\right)$ containing $0.025 \mathrm{mg} / \mathrm{mL}$ of 3-(Trimethylsilyl) propionic acid- $d 4$ sodium salt (TSP) was added as a lock solvent. One-dimensional NMR experiments were carried out using a Bruker Avance III $600 \mathrm{MHz}$ spectrometer (Bruker, Rheinstetten, Germany) equipped with a $5 \mathrm{~mm}$ triple resonance (TXI) probe at $298 \mathrm{~K}$. A standard Bruker noesypr $1 \mathrm{~d}\left(90^{\circ}-\mathrm{t}_{1}-90^{\circ}-\mathrm{d}_{\text {mix }}-90^{\circ}-\mathrm{FID}\right)$ sequence was used to suppress signals from water molecules, where $t_{1}$ is a $4 \mu$ s delay time and $d_{\text {mix }}$ is the mixing time. Acquisition parameters for the spectra were 64 scans, a spectral width of $7288 \mathrm{~Hz}$ collected into $32 \mathrm{~K}$ data points, an acquisition time of $2.24 \mathrm{~s}$ and an inter-scan relaxation delay of $5 \mathrm{~s}$. The Free Induction Decay (FID) obtained 
was multiplied by $0.3 \mathrm{~Hz}$ of exponential line broadening before Fourier transformation. The spectra were referenced to TSP (chemical shift $0 \mathrm{ppm}$ ), phased, and baseline corrected in Topspin 3.0 software (Bruker, Rheinstetten, Germany). SNR was measured using the built-in graphical interface in Topspin 3.0, where alanine $(1.47 \mathrm{ppm})$ was considered to be the signal, and spectra at lower frequency than $0 \mathrm{ppm}$ were considered to represent the noise region. Relative quantification of selected ${ }^{1} \mathrm{H}$ resonance was performed by integration of peak areas using Topspin 3.0 (Bruker). Assignments of ${ }^{1} \mathrm{H}$ NMR signals were carried out using Chenomx NMR Suite 7.7 (Chenomx, Canada) according to the Human Metabolome Database, ${ }^{25}$ and literature. ${ }^{14,18,26}$ In addition, heteronuclear single quantum coherence (HSQC) and total correlation spectroscopy (TOCSY) 2D NMR techniques were applied to confirm the identity of the assigned metabolites (see Figures S1 to S6 in supplementary material). The HSQC experiment was acquired with a spectral width of 7288 $\mathrm{Hz}$ in the ${ }^{1} \mathrm{H}$ dimension and $27164 \mathrm{~Hz}$ in the ${ }^{13} \mathrm{C}$ dimension, a matrix with size of $4096 \times 1024,512$ transients per increment and a relaxation delay of $2 \mathrm{~s}$. The TOCSY spectrum was acquired with acquired with a spectral width of $7288 \mathrm{~Hz}$ in the both ${ }^{1} \mathrm{H}$ dimension, a matrix with size of $2048 \times 512$, and an inter-scan relaxation delay of $2 \mathrm{~s}$. In addition, two-dimensional NMR experiments were carried out using a Bruker Avance III $800 \mathrm{MHz}$ spectrometer equipped with a 5mm 1H observe cryoprobe (Bruker Biospin, Rheinstetten, Germany). The HSQC experiment was acquired with a spectral width of $11961 \mathrm{~Hz}$ in the ${ }^{1} \mathrm{H}$ dimension and $33276 \mathrm{~Hz}$ in the ${ }^{13} \mathrm{C}$ dimension, a matrix with a size of $4096 \times 4096,512$ transients per increment and a relaxation delay of $1.5 \mathrm{~s}$. The TOCSY spectrum was acquired with a spectral width of $9578 \mathrm{~Hz}$ in both ${ }^{1} \mathrm{H}$ dimensions, a matrix with a size of $8192 \times 1536$, and an inter-scan relaxation delay of $1.8 \mathrm{~s}$. 
144 Multivariate Data analysis

$145{ }^{1} \mathrm{H}$ NMR spectra were imported to Matlab R2010b (The Mathworks, Inc., USA), and the 146 misalignments of the spectra were corrected using the icoshift algorithm, based on the correlational 147 shifting of spectral intervals. ${ }^{27}$ The spectrum with the highest correlation to the rest of the spectra in 148 the matrix was used as a reference. The 9.5 to $12 \mathrm{ppm}$ and 0.5 to $-1.2 \mathrm{ppm}$ regions and the region 149 containing residual water resonance (4.8. to $4.7 \mathrm{ppm}$ ) were removed from the aligned spectra. The 150 spectra were normalized to unit area and pareto-scaled before principal component analysis (PCA) 151 using the PLS Toolbox (Eigenvector Research, USA) in MATLAB20010b. 


\section{Results and discussion}

The ${ }^{1} \mathrm{H}$ NMR spectra obtained from fresh fecal samples revealed the presence of a wide range of metabolites. Figure 1 shows a representative spectrum of a fecal sample extracted in PBS buffer. The obtained ${ }^{1} \mathrm{H}$ NMR spectra contained resonances from short chain fatty acids (predominantly acetate, propionate, and butyrate), branched-chain fatty acids (iso-valerate, iso-butyrate), biogenic amines (trimethylamine and dimethylamine), organic acids (succinate, fumarate), carbohydrates (glucose predominant), and amino acids (leucine, isoleucine, valine, tyrosine, phenylalanine, and others). Figure 1 and the numbering scheme outlined in Table 1 summarize the assigned resonances of the fresh fecal samples. To the best of our knowledge, we report here for the first time signals from the metabolites xylose, arabinose, nicotinate, orotic acid, malic acid, xanthine, thymine, and acetoin in the fecal extract using ${ }^{1} \mathrm{H}$ NMR spectroscopy.

\section{Evaluation of extraction solvents}

The influence of solvent: water, $\mathrm{D}_{2} \mathrm{O}$, PBS buffer, and mixed solvent (methanol/chloroform/water) on extraction of the fecal metabolites was evaluated by assessing the metabolite compositions in the NMR profile obtain from the different extracts. This analysis revealed that the signals from n-acetyl compounds, lipid residue, and some unknown anomeric hydrogen in carbon signals 5.0-5.5 ppm were preferentially extracted in the methanol extract (Figure S7, supplementary information). In contrast, the resonance from trimethylamine appeared only in the ${ }^{1} \mathrm{H}$ NMR spectra of the extracts from distilled water, $\mathrm{D}_{2} \mathrm{O}$, or PBS buffer. Signals from SCFA, amino acids, and organic acids were similar in the four extracts, however, recoveries differed.

The methanol/chloroform/water extraction is time-consuming, labor-intensive, expensive, and toxic (hazardous) compared to the one-solvent extractions. As PBS buffer extraction reduces intersample $\mathrm{pH}$ variation during extraction, we suggest PBS buffer as the best choice for extraction 
solvent. However, the lipid-containing organic (chloroform) phase in the

177 methanol/chloroform/water provides complementary information about the non-polar metabolites in

178 the feces, which presently has not been investigated thoroughly by using NMR-based

179 metabolomics. The NMR signals recorded on chloroform phase in the non-polar extracts were

180 assigned to different lipid classes/functional groups. Our result indicates the presence of unsaturated

181 fatty acids, triacylglycerides, glycerol backbone of phospholipid, phosphatidylcholine, alkyl chains,

182 and acyl saturated chains in the proton NMR spectra of the lipid extracts. These signals

183 predominantly from the saturated and unsaturated fatty acids are comparable to the lipid signals in

184 the other body fluid such as plasma and the tissue samples. Assignments of ${ }^{1} \mathrm{H}$ NMR lipid signals

185 were carried out using the American Oil Chemist Society (AOCS) Lipid library ${ }^{28}$ and literature.

$186{ }^{29,30}$ In future, examination of these fatty acid compositions in feces might have great potential to 187 reveal mechanistic interplay between the gut microbiota and lipid metabolism.

\section{Effect of varying the Wf:Vb ratio during extraction}

190 Theoretically, concentrated samples are beneficial in NMR spectroscopy as SNR will increase with increasing amount of compound. However, in metabolomics concentrated samples at the same time retain a challenge as they potentially may lack signal stability due to $\mathrm{pH}$ variations and intermolecular interactions. Therefore, in the present study the possible tradeoffs of chemical shift stability and signal intensity were investigated in a detailed comparison of three buffer ratios 195 (dilutions) and two sample treatments. Three different buffer dilutions (1:2, 1:5, and 1:10) and the effect of sample treatments (sonication and freeze-thaw cycles) during fecal metabolite extraction were evaluated. The effects of sonication and freeze-thaw cycles were less pronounced when compared to the effect of varying buffer concentration on the fecal metabolite extraction (Figure 3 ). 
shows that 1:2 extracts have higher SNR in comparison to 1:5 and 1:10 extracts (Figure 3), which can be ascribed to the dilution of metabolites during extraction in the 1:5 and 1:10 samples. Visual inspection of the spectra (scaled by the dilution factor) showed that the intensities of the metabolites and the noise in the spectra were different in the 1:2 extract when compared to the 1:5 and 1:10 extracts (Figure 4). The signals from nicotinate, UDP glucose, tryptophan, bile acids are masked by higher contribution from noise in the 1:5 and 1:10 extracts compared to the 1:2 extract (Figure 4). In contrast, the signal from the n-acetyl compound had lower signal intensity in the 1:2 extract compared to 1:5 and 1:10 (data not shown). The lower intensity of n-acetyl compound in 1:2 extract can likely be ascribed to saturation of metabolites during extraction. In addition to signal intensity of metabolites in the NMR spectrum, the recovery of a metabolite during extraction is essential. Consequently, in order to measure recovery, feces were spiked with maleic acid, dimethyl sulfone, and succinic acid. The results showed that the recovery yield of these standards is minor influenced by dilution factor (Table 2). Nevertheless, the overall results implicate that the $\mathrm{Wf}$ : $\mathrm{Vb}$ affects the detection and quantification of certain metabolites when extracted with a high buffer volume (Figure 4). Thereby, based on our finding it is likely that proper choice of solvent and the weight-tobuffer volume during feces extraction might have an impact in the outcome/understanding of the nutritional metabolomics study.

\section{Inter-sample $\mathbf{p H}$ consistency}

In general, the $\mathrm{pH}$ of human feces can range from 6.8 to 7.0 , and the variation usually depends on diet, xenobiotic intake and/or the health status of the individual. For effective subsequent data mining, inter-sample $\mathrm{pH}$ consistency remains a critical problem because this variability can result in chemical shift variations of the metabolites. Although some peak alignment techniques can minimize the chemical shift inconsistency in the data after NMR acquisition, chemical shift 
224 variations still create ambiguity for overlapping and unknown signals. ${ }^{31}$ Therefore, the most 225 efficient strategy is to minimize such inter-sample $\mathrm{pH}$ variations during sample preparation i.e., 226 prior to data acquisition. In the present study, we measured the inter sample $\mathrm{pH}$ variation for the 227 three different buffer concentrations (1:2, 1:5, and 1:10) and sample treatments (sonication and 228 freeze-thaw). Differences in $\mathrm{pH}$ between the samples due to sample treatment were minor in comparison with the effects of the $\mathrm{Wf}: \mathrm{Vb}$ ratio of buffer (Figure $\mathrm{S} 8$, supplementary information). The $\mathrm{pH}$ of the fecal sample increased with an increase in the $\mathrm{Wf}: \mathrm{Vb}$ ratio of buffer. The samples extracted with a $\mathrm{Wf}: \mathrm{Vb}$ ratio of 1:10 and 1:5 showed more stable $\mathrm{pH}$ in the range of 7.30 to 7.45 , while the samples extracted with a 1:2 $\mathrm{Wf:} \mathrm{Vb}$ ratio varied in $\mathrm{pH}$ from 7.20 to 7.40 . Even though the $233 \mathrm{pH}$ was marginally more stable between the samples extracted with 1:5 and 1:10 Wf:Vb ratios, the SNR was reduced more than 2-fold and, the variations in the chemical shifts for the samples samples are taken in consideration. 


\section{Reproducibility}

247 To address the suitability of a methodology to profile metabolites in metabolomics studies, the 248 reproducibility of the method should be evaluated. Pareto-scaled normalized NMR spectra obtained 249 at three different time points from 5 individuals (extracted with a $\mathrm{Wf}: \mathrm{Vb}$ ratio of 1:2) were analyzed 250 by multivariate data analysis to elucidate the reproducibility of the method. The PCA score plot in 251 Figure 5 shows that the individual samples (represented by the colors) were clustered together 252 depicting the reproducibility of the extraction methodology. In addition, the data from this study 253 also revealed distinct inter-individual variation supporting the fact that the sample preparation 254 method was capable of detecting and identifying metabolic differences among individuals. 255 Intriguingly, the samples from two subjects (depicted as green and cyan) did not cluster together as 256 observed for the other three subjects (Figure 5). During extraction, the presence of undigested food 257 residuals were clearly observed in these samples compared to the rest of other samples. The presence of these food residuals could affect the NMR profile of the fecal extract. Therefore, it may be worthwhile to perform BSS which could for instance indicate that the observed differences within the samples may be due to larger variation in the stool consistency of the individuals.

To eliminate inter-individual differences and assess the reproducibility performance of the metabolites, extraction was done in triplicate using different $\mathrm{Wf}$ : $\mathrm{Vb}$ ratio $(1: 2,1: 5$, and 1:10) from considerably higher $\% \mathrm{CV}$ when extracted at 1:5 and 1:10 dilution ratio respectively, when compared to metabolites extracted with the 1:2 dilution ratio. This could possibly be ascribed to the 
previously. This difference most probably affected the recoveries of fumarate and formate, indicating they were preferentially extracted in lower $\mathrm{pH}$. Considering the recovery would be different for specific class of compound, the main purpose for metabolic profiling/metabolomics study is to obtain reproducible spectra that can be on compared with each other. Intriguingly, based on our results, it is also noteworthy that $\mathrm{Wf}: \mathrm{Vb}$ ratio of 1:2 showed reproducible result during extraction under the conditions tested. Thus, we suggest that the $\mathrm{Wf}: \mathrm{Vb}$ ratio affects the reproducibility of certain metabolites when extracted with a diluted buffer.

\section{Fecal NMR profile stability study}

The NMR experiments may last from a few minutes to hours of acquisition time. During NMR acquisition, the metabolites might change over time due to either enzymatic or non-enzymatic processes. Thus, it is essential to elucidate spectral changes that might occur over time. Therefore, ${ }^{1} \mathrm{H}$ NMR spectra were acquired over a period of 12 hours by repeating the acquisition at regular intervals of 2 hours (Figure S10 and S11). The obtained spectra were analyzed by overlaying the spectra from all acquired time points. The results showed that the metabolite profile of the fecal extracts remained stable over the $12 \mathrm{~h}$ period.

\section{Conclusions}

Fecal-based metabolomics is a rapidly emerging discipline. An optimized sample preparation is crucial for metabolomics studies, and here we suggest buffer extraction might be the most suitable approach to extract metabolic information in the feces. The study demonstrates that a $\mathrm{Wf}: \mathrm{Vb}$ ratio of 1:2 might be optimal quality for ${ }^{1} \mathrm{H}$ NMR spectroscopic data for metabolomics data of human feces, while the effects of sonication and freeze-thaw were less pronounced of the condition tested. 
293 More than 60 metabolites have been assigned from the ${ }^{1} \mathrm{H}$ NMR spectra obtained, and to our 294 knowledge, some of the metabolites are reported here for the very first time using NMR spectra 295 acquired on fecal extracts.

\section{Acknowledgement}

298 The present study is part of the Ph.D. work of Santosh Lamichhane and was financially supported 299 by DuPont, Food Future Innovation (FFI), and Aarhus University. The authors also wish to thank 300 the Danish research council FTP for financial support through the project 'Advances in food and 301 nutrition research through implementation of metabolomics technologies' (\#274-09-0107)'. The $302800 \mathrm{MHz}$ spectra NMR spectra were obtained at the Danish Instrument Center for NMR 303 spectroscopy of Biological Macromolecules.

\section{Supporting Information Available}

305 Supplementary method section on metabolite extraction methods and Figure S1 to S11. This 306 information is available free of charge via the Internet at http://pubs.acs.org/ 


\section{Figure Captions}

Figure 1. Representative ${ }^{1} \mathrm{H}$ NMR spectrum of a human fecal sample extracted in PBS buffer. A) 0.7 to $4.55 \mathrm{ppm}$; B) 4.9 to $8.55 \mathrm{ppm} \mathrm{C)} 8.6$ to $9.8 \mathrm{ppm}$. The aromatic region in the spectrum (8.6 to $9.8 \mathrm{ppm}$ ) has been magnified three times as compared to the region B. The inserts show additional signals detected in spectra obtained on other human fecal samples. Keys to the figure are given in Table 2.

Figure 2. Representative ${ }^{1} \mathrm{H}$ NMR spectrum of a human fecal sample extracted in organic (chloroform) phase in the methanol/chloroform/water extract. A) 5.7 to 4.7, double bond section; UFA = unsaturated fatty acids; TAG = triacylglycerides, Glyc-B = glycerol backbone of phospholipid. B) 4.4 to 2.8 regions; $\mathrm{PC}=$ phosphatidylcholine. C) Alkyl and Acyl saturated chains

Figure 3. Average SNR ratios from the fecal extracts with different $\mathrm{Wf}$ : $\mathrm{Vb}$ and obtained with sonication and without sonication, respectively $(n=4)$. The alanine signal at $1.44 \mathrm{ppm}$ was used for the calculation of SNR. Error bars show standard deviations.

Figure 4. Representative ${ }^{1} \mathrm{H}$ NMR spectra of human fecal extracts with varying Wf: Vb ratios A) $1: 10$ B) $1: 5$ C) $1: 2$.

Figure 5. PCA scores plot showing reproducibility for fecal extracts with $\mathrm{Wf}$ : Vb ratio 1:2. Each symbol represents an individual. The number 1, 2, 3 illustrates the samples from same individual collected during 3 different time periods.

Figure 6. The coefficient of variation (\% CV) of eleven different metabolites from NMR measurement of the fecal extract (three different buffer dilutions 1:2, 1:5, and 1:10). 


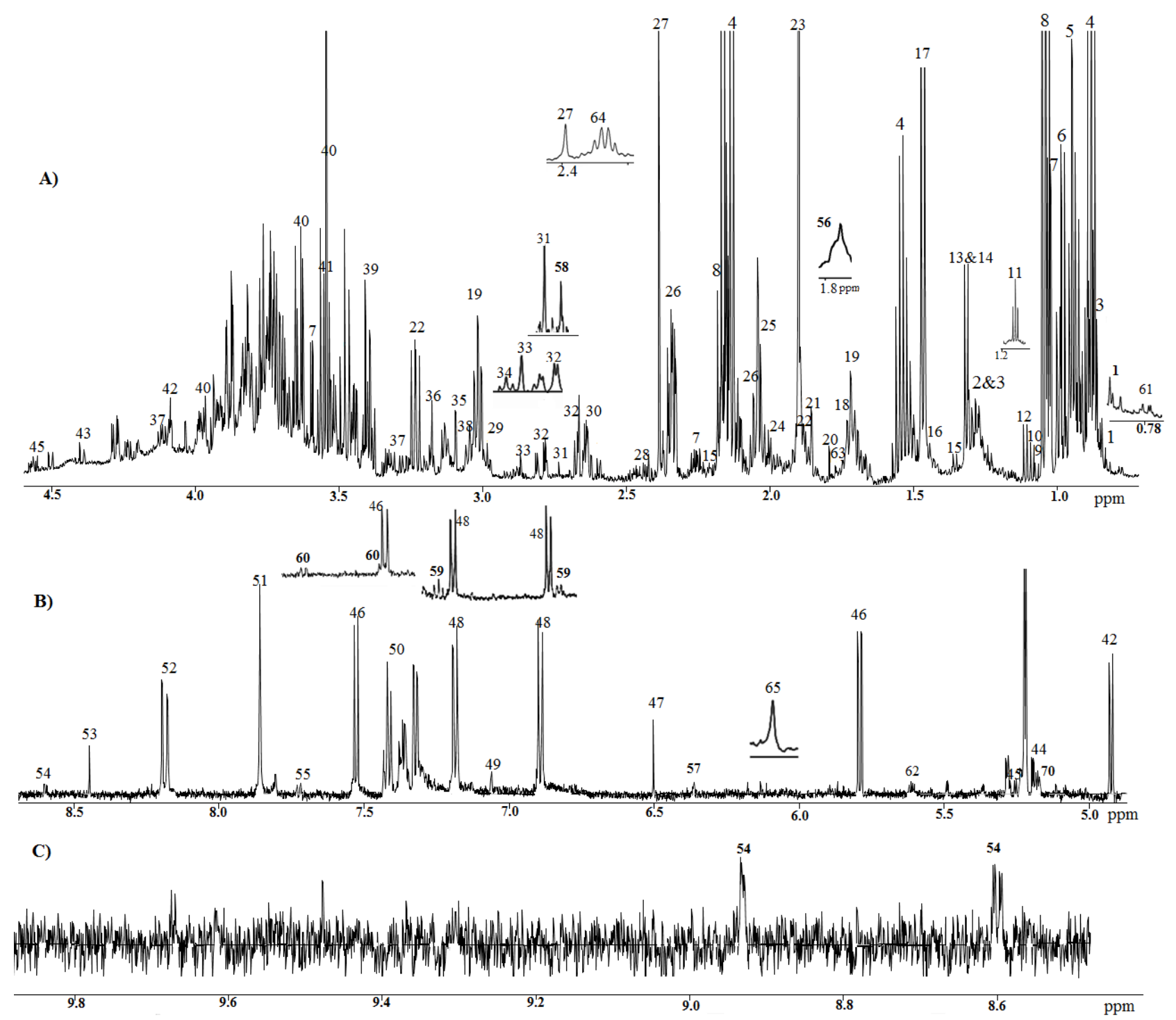

Figure 1. 

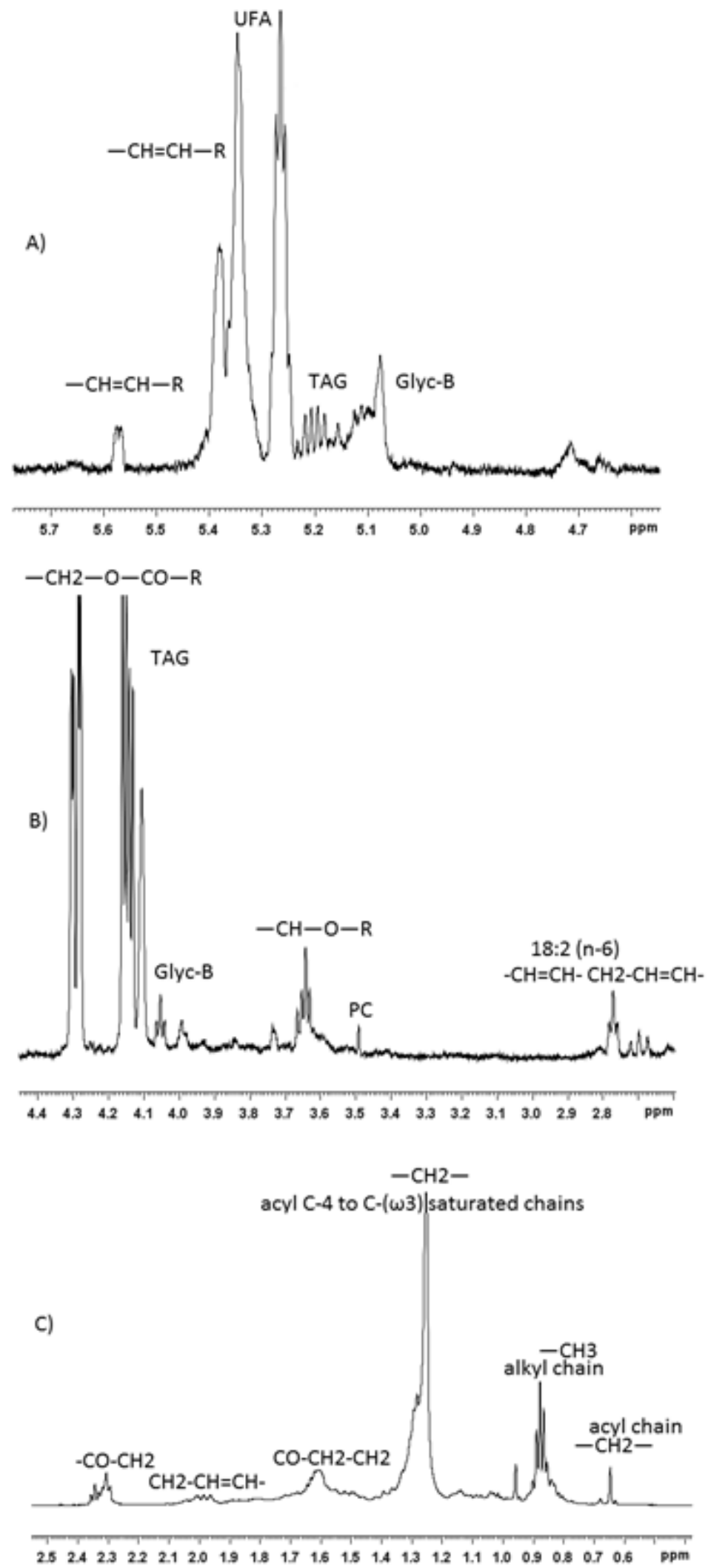

Figure 2. 


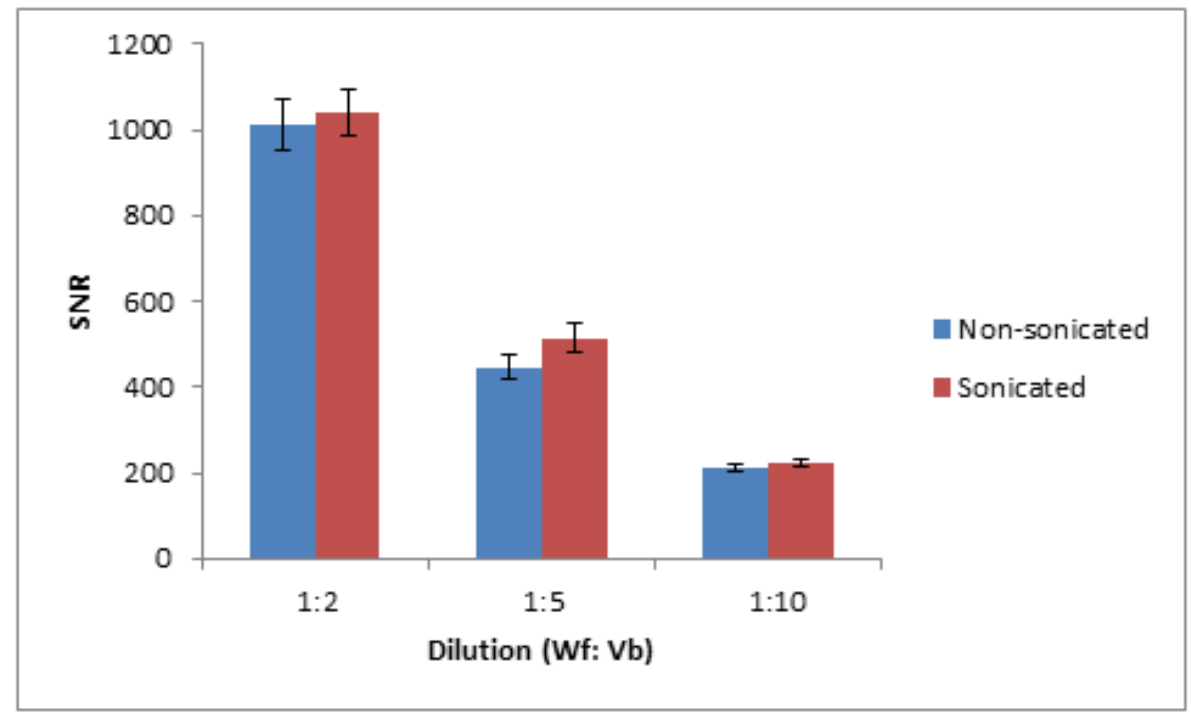

Figure 3. 


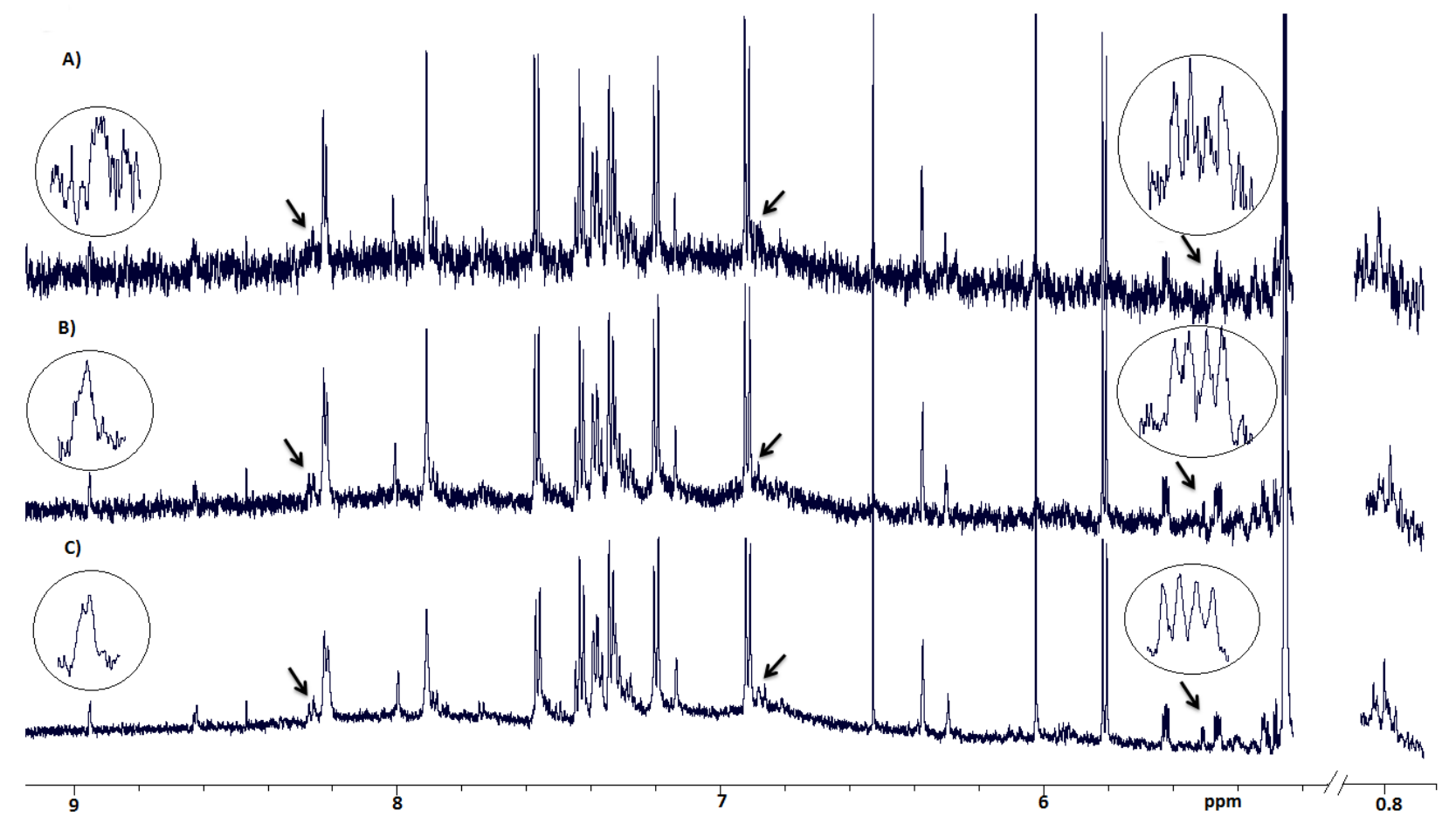

Figure 4. 


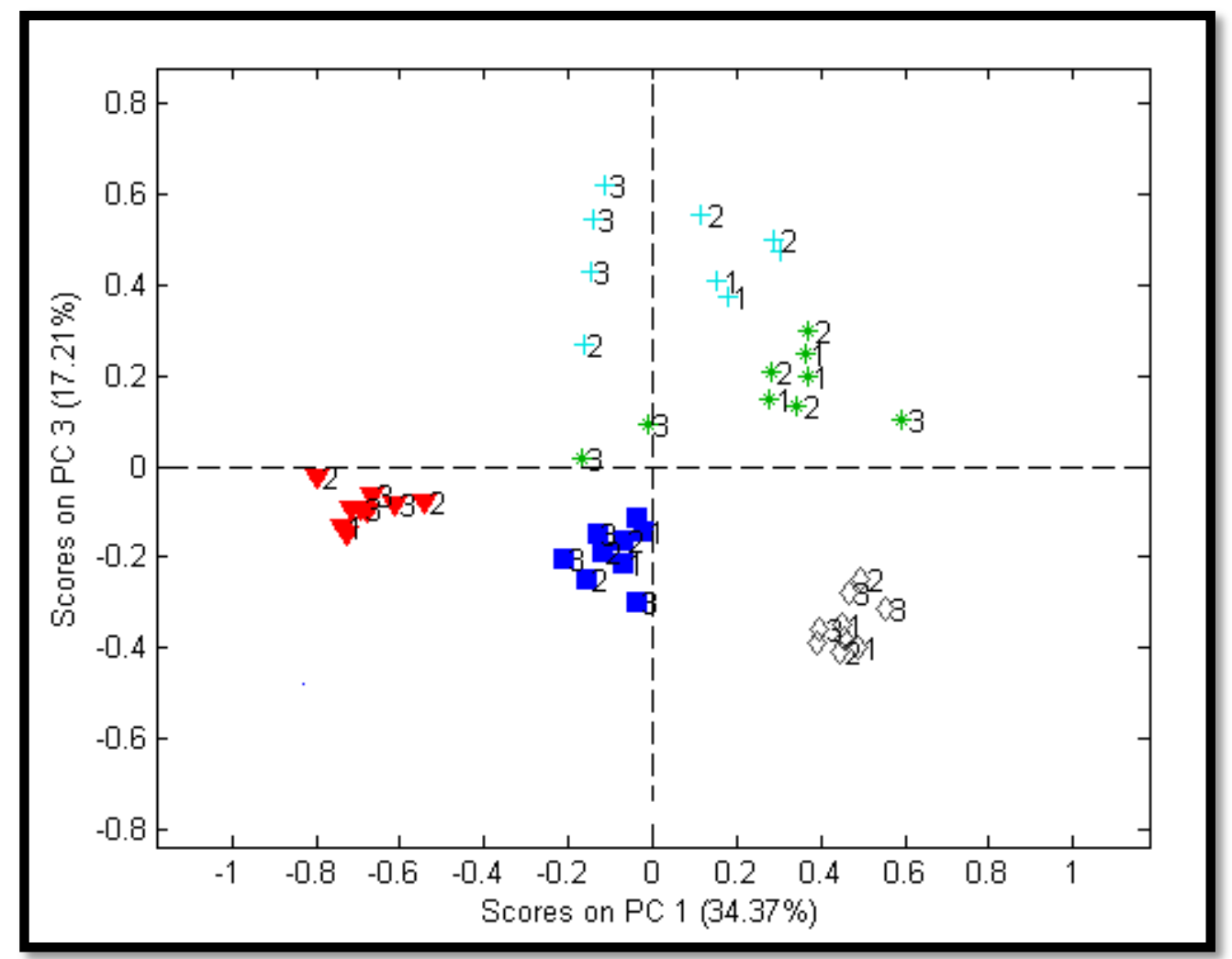

Figure 5. 


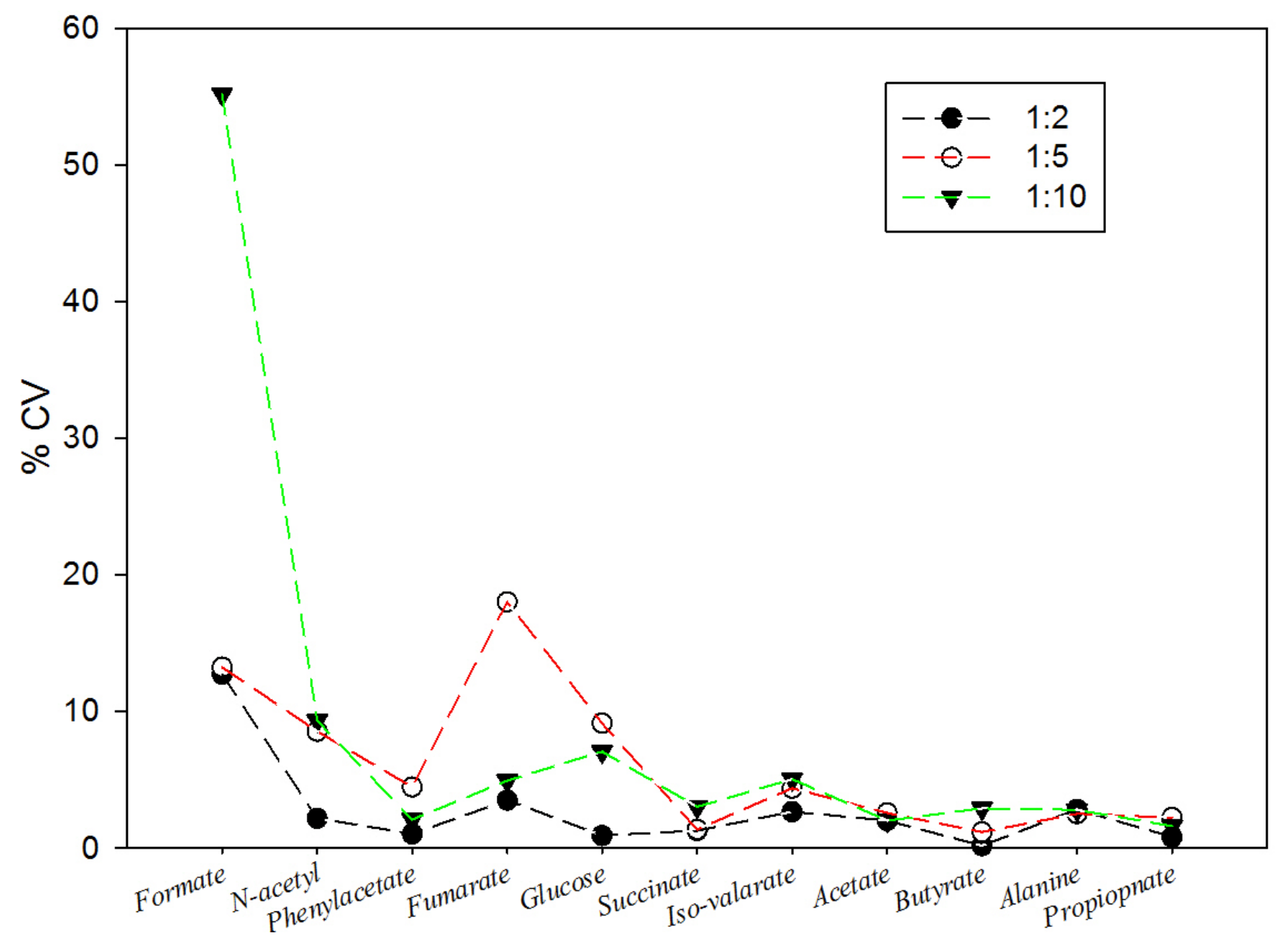

Figure 6. 
Table 1. ${ }^{1} \mathrm{H}$ NMR Chemical Shifts and Assignments of Metabolites Detected in Human Fecal Extracts

\begin{tabular}{|c|c|c|}
\hline No. & Compound & Proton Chemical shift in ppm and multiplicity \\
\hline 1 & 2-methyl butyrate ${ }^{a}$ & $0.86(\mathrm{t}), 1.05(\mathrm{~d}), 1.38(\mathrm{~m}), 1.5(\mathrm{~m}), 2.21(\mathrm{~m})$ \\
\hline 2 & caprylate & $0.85(\mathrm{t}), 1.27(\mathrm{~m}), 1.53(\mathrm{~m}), 2.16(\mathrm{t})$ \\
\hline 3 & valerate & $0.88(\mathrm{t}), 1.31(\mathrm{~m}), 1.54(\mathrm{~m}), 2.18(\mathrm{~m})$ \\
\hline 4 & n-butyrate & $0.91(\mathrm{t}), 1.56(\mathrm{t}), 2.16(\mathrm{t})$ \\
\hline 5 & leucine & $0.96(\mathrm{~d}), 0.97(\mathrm{~d}), 1.7(\mathrm{~m})$ \\
\hline 6 & iso-leucine & $0.94(\mathrm{t}), 1.02(\mathrm{~d}), 1.27(\mathrm{~m})$ \\
\hline 7 & valine & $0.99(\mathrm{~d}), 1.05(\mathrm{~d}), 2.3(\mathrm{~m})$ \\
\hline 8 & propionate & $1.06(\mathrm{t}), 2.19(\mathrm{~m})$ \\
\hline 9 & methyl succinate & $1.08(\mathrm{~d}), 2.11(\mathrm{dd}), 2.51(\mathrm{~d}), 2.61(\mathrm{~m})$ \\
\hline 10 & iso butyrate & $1.12(\mathrm{~d}), 2.40(\mathrm{~m})$ \\
\hline 11 & ethanol & $1.18(\mathrm{t}), 3.6(\mathrm{q})$ \\
\hline 12 & 3-methyl 2oxovalerate ${ }^{a}$ & $0.89(\mathrm{t}), 1.10(\mathrm{~d}), 1.46(\mathrm{~m}), 1.70(\mathrm{~m}), 2.93(\mathrm{~m})$ \\
\hline 13 & threonine & $1.33(\mathrm{~d}), 3.57(\mathrm{~d}), 4.24(\mathrm{~m})$ \\
\hline 14 & lactate & $1.31(\mathrm{~d}), 4.1(\mathrm{q})$ \\
\hline 15 & acetoin & $1.37(\mathrm{~d}), 2.20(\mathrm{~s}), 4.42(\mathrm{q})$ \\
\hline 16 & iso-caproate & $0.88(\mathrm{~d}), 1.45(\mathrm{~m}), 1.49(\mathrm{~m}), 2.19(\mathrm{t})$ \\
\hline 17 & alanine & $1.48(\mathrm{~d}), 3.78(\mathrm{q})$ \\
\hline 18 & cadavarine & $1.46(\mathrm{~m}), 1.73(\mathrm{~m}), 3.02(\mathrm{~m})$ \\
\hline 19 & lysine & $1.40(\mathrm{~m}), 1.70(\mathrm{~m}), 3.03(\mathrm{t}), 3.72(\mathrm{t})$ \\
\hline 20 & unknown singlet & $1.81(\mathrm{~s})$ \\
\hline 21 & thymine & $1.87(\mathrm{~s}), 7.39(\mathrm{~s})$ \\
\hline 22 & arginine & $1.68(\mathrm{~m}), 1.91(\mathrm{~m}), 3.23(\mathrm{t}), 3.76(\mathrm{t})$ \\
\hline 23 & acetate & $1.92(\mathrm{~s})$ \\
\hline 24 & n-acetylglutamate & $2.02(\mathrm{~s}), 2.05(\mathrm{~m}), 4.1(\mathrm{~m})$ \\
\hline 25 & iso-valerate & $2.06(\mathrm{~d}), 1.98(\mathrm{~m}), 0.91(\mathrm{~d})$ \\
\hline 26 & glutamate & $2.14(\mathrm{~m}), 2.46(\mathrm{~m}), 3.78(\mathrm{~m})$ \\
\hline 27 & succinate & $2.41(\mathrm{~s})$ \\
\hline 28 & glutamine & $2.12(\mathrm{~m}), 2.44(\mathrm{~m}), 3.75(\mathrm{t})$ \\
\hline 29 & 5 aminopentonate ${ }^{\mathrm{a}}$ & $3.02(\mathrm{t}), 2.21(\mathrm{t}), 1.69(\mathrm{~m}), 1.65(\mathrm{~m})$ \\
\hline 30 & methionine & $2.15(\mathrm{~m}), 2.63(\mathrm{t}), 3.85(\mathrm{dd})$ \\
\hline 31 & sarcosine $^{\mathrm{a}}$ & $2.72(\mathrm{~s}), 3.6(\mathrm{~s})$ \\
\hline 32 & aspartate & $2.69(\mathrm{dd}), 2.82(\mathrm{dd}), 3.91(\mathrm{dd})$ \\
\hline 33 & trimethylamine & $2.87(\mathrm{~s})$ \\
\hline 34 & 3-phenylpropionate ${ }^{\text {a }}$ & $2.87(\mathrm{t}), 2.47(\mathrm{t}), 7.26(\mathrm{t}), 7.32(\mathrm{~d}), 7.36(\mathrm{t})$ \\
\hline 35 & malonate & $3.11(\mathrm{~s})$ \\
\hline 36 & choline & $3.27(\mathrm{~s}), 3.53(\mathrm{~m})$ \\
\hline 37 & proline & $1.98(\mathrm{~m}), 2.06(\mathrm{~m}), 2.34(\mathrm{~m}), 3.32(\mathrm{dt}), 3.34(\mathrm{~m})$ \\
\hline 38 & ornithine & $1.72(\mathrm{~m}), 1.82(\mathrm{~m}), 1.93(\mathrm{~m}), 3.03(\mathrm{t}), 3.77(\mathrm{t})$ \\
\hline 39 & glucose & $3.40(\mathrm{t}), 3.53(\mathrm{dd}), 3.71(\mathrm{t}) 3.73(\mathrm{dd}), 3.83(\mathrm{~m}), 5.24(\mathrm{~d})$ \\
\hline 40 & glycerol & $3.64(\mathrm{~m}), 3.78(\mathrm{~m})$ \\
\hline 41 & glycine & $3.57(\mathrm{~s})$ \\
\hline 42 & ribose & $\begin{array}{l}3.52(\mathrm{~m}), 3.60(\mathrm{~m}), 3.91(\mathrm{~m}), 4.10(\mathrm{~m}), 4.20(\mathrm{dd}), 4.92 \\
(\mathrm{~d}), 5.25(\mathrm{~d}),\end{array}$ \\
\hline
\end{tabular}




\begin{tabular}{|c|c|c|}
\hline 43 & dihydroxyacetone & $4.41(\mathrm{~s})$ \\
\hline 44 & xylose & $5.19(\mathrm{~d}), 4.57(\mathrm{~d}), 3.92(\mathrm{dd}), 3.89(\mathrm{dd}), 5.18(\mathrm{~d}), 3.31(\mathrm{~d})$ \\
\hline 45 & galactose & $3.54(\mathrm{dd}), 3.65(\mathrm{dd}), 3.72(\mathrm{~m}), 3.82(\mathrm{~m}), 4.06(\mathrm{t}), 5.26(\mathrm{~d})$ \\
\hline 46 & uracil & $5.78(d), 7.49(d)$ \\
\hline 47 & fumarate & $6.52(\mathrm{~s})$ \\
\hline 48 & tyrosine & $6.91(\mathrm{~d}), 7.20(\mathrm{~d})$ \\
\hline 49 & histidine & $3.16(\mathrm{dd}), 3.23(\mathrm{dd}), 3.98(\mathrm{dd}), 6 . .99(\mathrm{~d}), 7.83(\mathrm{~s})$ \\
\hline 50 & phenylalanine & $3.54(\mathrm{~s}), 7.31(\mathrm{~m}), 7.37(\mathrm{~m})$ \\
\hline 51 & xanthine & $7.94(\mathrm{~s})$ \\
\hline 52 & hypoxanthine & $8.12(\mathrm{~s}), 8.21(\mathrm{~s})$ \\
\hline 53 & formate & $8.46(\mathrm{~s})$ \\
\hline 54 & nicotinate & $7.56(\mathrm{dd}), 8.28(\mathrm{~m}), 8.66(\mathrm{dd}), 8.94(\mathrm{~d})$ \\
\hline 55 & p-cresol & $2.25(\mathrm{~s}), 6.87(\mathrm{~m}), 7.18(\mathrm{~d})$ \\
\hline 56 & putresine & $1.77(\mathrm{~m}), 3.06(\mathrm{~m})$ \\
\hline 57 & urocanic acid $^{\mathrm{a}}$ & $6.38(\mathrm{~d}), 7.27(\mathrm{~d}), 7.87(\mathrm{~s})$ \\
\hline 58 & dimethylamine & $2.74(\mathrm{~s})$ \\
\hline 59 & 3 hydoxyphenlyacetate ${ }^{a}$ & $3.56(\mathrm{~s}), 6.93(\mathrm{~m}), 7.21(\mathrm{~m})$ \\
\hline 60 & tryptophan & $7.19(\mathrm{~m}), 7.31(\mathrm{~m}), 7.53(\mathrm{~d}), 7.76(\mathrm{~d})$ \\
\hline 61 & bile acid & $0.78(\mathrm{~m})$ \\
\hline 62 & UDP glucose $^{\mathrm{a}}$ & $5.62(\mathrm{dd}), 6.0(\mathrm{~m})$ \\
\hline 63 & glutarate & $1.8(\mathrm{t}), 2.19(\mathrm{t})$ \\
\hline 64 & malic acid & $2.33(\mathrm{dd}), 2.65(\mathrm{dd}), 4.28(\mathrm{dd})$ \\
\hline 65 & orotic acid & $6.19(\mathrm{~s})$ \\
\hline 66 & n-acetyl group's & $2.04(\mathrm{~s}) .7,88(\mathrm{~s})$ \\
\hline 67 & ethanolamine & $3.12(\mathrm{t}), 3.80(\mathrm{t})$ \\
\hline 68 & allantion $^{\mathrm{a}}$ & $5.38(\mathrm{~s})$ \\
\hline 69 & glycerophosphocholine & $3.19(\mathrm{~s})$ \\
\hline 70 & arabinose & $5.24(\mathrm{~d}), 4.52(\mathrm{~d}), 3.95(\mathrm{~m}), 3.89(\mathrm{~m}), 3.52(\mathrm{dd})$ \\
\hline
\end{tabular}

${ }^{\mathrm{a}}$ Assignment with best matched signals 
Table 2. Comparison of Yields of Standard Compounds with Different Wf: Vb during Extraction 308

\begin{tabular}{|c|c|c|c|}
\hline Standards & Wf:Vb & Wf:Vb & Wf:Vb \\
\hline & $1: 2$ & $1: 5$ & $1: 10 \quad 310$ \\
\hline Sucincate & $3.06 \pm 0.02$ & $3.11 \pm 0.04$ & $3.06 \pm 0.091$ \\
\hline Dimthylsulphone & $3.51 \pm 0.05$ & $3.48 \pm 0.02$ & $3.50 \pm 0.05$ \\
\hline
\end{tabular}

Means ( \pm ) SD determined from the integrals of the compounds relative to that of maleic acid 


\section{References}

(1) Averna, T. A.; Kline, E. E.; Smith, A. Y.; Sillerud, L. O. J. Urol. 2005, 173, 433-438.

(2) Beckonert, O.; Keun, H. C.; Ebbels, T. M.; Bundy, J.; Holmes, E.; Lindon, J. C.; Nicholson, J. K. Nat. Protoc 2007, 2, 2692-2703.

(3) Bertram, H. C.; Eggers, N.; Eller, N. Anal. Chem 2009, 81, 9188-9193.

(4) Bertram, H. C.; Malmendal, A.; Petersen, B. O.; Madsen, J. C.; Pedersen, H.; Nielsen, N. C.; Hoppe, C.; Mølgaard, C.; Michaelsen, K. F.; Duus, J. Ø. Anal. Chem 2007, 79, 7110-7115.

(5) Bäckhed, F.; Ding, H.; Wang, T.; Hooper, L. V.; Gou, Y. K.; Nagy, A.; Semenkovich, C. F.; Gordon, J. I. PNAS 2004, 101, 15718-15723.

(6) Gao, X.; Pujos-Guillot, E.; Sebedio, J. L. Anal. Chem 2010, 82, 6447-6456.

(7) Hooper, L. V.; Midwedt, T.; Gordon, J. I. In Ann. Rev. Nutr., 2002, pp 283-307.

(8) Nicholson, J. K.; Holmes, E.; Kinross, J.; Burcelin, R.; Gibson, G.; Jia, W.; Pettersson, S. Science 2012, 336, 1262-1267.

(9) Turnbaugh, P. J.; Ley, R. E.; Mahowald, M. A.; Magrini, V.; Mardis, E. R.; Gordon, J. I. Nature 2006, 444, 1027-1031.

(10) Rath, C. M.; Alexandrov, T.; Higginbottom, S. K.; Song, J.; Milla, M. E.; Fischbach, M. A.; Sonnenburg, J. L.; Dorrestein, P. C. Anal. Chem 2012, 84, 9259-9267.

(11) Gregory, K. E.; Bird, S. S.; Gross, V. S.; Marur, V. R.; Lazarev, A. V.; Walker, W. A.; Kristal, B. S. Anal. Chem 2013, 85, 1114-1123.

(12) Rezzi, S.; Ramadan, Z.; Fay, L. B.; Kochhar, S. J. Proteome Res. 2007, 6, 513-525.

(13) Lamichhane, S.; Yde, C. C.; Forssten, S.; Ouwehand, A. C.; Saarinen, M.; Jensen, H. M.; Gibson, G. R.; Rastall, R.; Fava, F.; Bertram, H. C. J Agri Food Chem 2014, 62, 9944-9951.

(14) Le Gall, G.; Noor, S. O.; Ridgway, K.; Scovell, L.; Jamieson, C.; Johnson, I. T.; Colquhoun, I. J.; Kemsley, E. K.; Narbad, A. J. Proteome Res. 2011, 10, 4208-4218. 
(15) Marchesi, J. R.; Holmes, E.; Khan, F.; Kochhar, S.; Scanlan, P.; Shanahan, F.; Wilson, I. D.; Wang, Y.J. Proteome Res. 2007, 6, 546-551.

(16) Monleón, D.; Morales, J. M.; Barrasa, A.; López, J. A.; Vázquez, C.; Celda, B. NMR Biomed. 2009, 22, 342-348.

(17) Martin, F. P. J.; Sprenger, N.; Montoliu, I.; Rezzi, S.; Kochhar, S.; Nicholson, J. K. J. Proteome Res. 2010, 9, 5284-5295.

(18) Jacobs, D. M.; Deltimple, N.; van Velzen, E.; van Dorsten, F. A.; Bingham, M.; Vaughan, E. E.; van Duynhoven, J. NMR Biomed. 2008, 21, 615-626.

(19) Saric, J.; Wang, Y.; Li, J.; Coen, M.; Utzinger, J.; Marchesi, J. R.; Keiser, J.; Veselkov, K.; Lindon, J. C.; Nicholson, J. K.; Holmes, E. J. Proteome Res. 2008, 7, 352-360.

(20) Pettersson, J.; Karlsson, P. C.; Choi, Y. H.; Verpoorte, R.; Rafter, J. J.; Bohlin, L. Biol. Pharm. Bullet. 2008, 31, 1192-1198.

(21) Ndagijimana, M.; Laghi, L.; Vitali, B.; Placucci, G.; Brigidi, P.; Guerzoni, M. E. Int. J. Food Microbiol. 2009, 134, 147-153.

(22) Romick-Rosendale, L. E.; Goodpaster, A. M.; Hanwright, P. J.; Patel, N. B.; Wheeler, E. T.; Chona, D. L.; Kennedy, M. A. Magn. Reson. Chem. 2009, 47, S36-S46.

(23) Zhao, Y.; Wu, J.; Li, J. V.; Zhou, N. Y.; Tang, H.; Wang, Y. J. Proteome Res. 2013, 12, 29872999.

(24) Wu, J.; An, Y.; Yao, J.; Wang, Y.; Tang, H. Analyst 2010, 135, 1023-1030.

(25) Wishart, D. S.; Knox, C.; Guo, A. C.; Eisner, R.; Young, N.; Gautam, B.; Hau, D. D.; Psychogios, N.; Dong, E.; Bouatra, S.; Mandal, R.; Sinelnikov, I.; Xia, J.; Jia, L.; Cruz, J. A.; Lim, E.; Sobsey, C. A.; Shrivastava, S.; Huang, P.; Liu, P.; Fang, L.; Peng, J.; Fradette, R.; Cheng, D.; Tzur, D.; Clements, M.; Lewis, A.; de souza, A.; Zuniga, A.; Dawe, M.; Xiong, Y.; Clive, D.; 
Greiner, R.; Nazyrova, A.; Shaykhutdinov, R.; Li, L.; Vogel, H. J.; Forsythei, I. Nucleic Acids Res. 2009, 37, D603-D610.

(26) Bojstrup, M.; Petersen, B. O.; Beeren, S. R.; Hindsgaul, O.; Meier, S. Anal. Chem. 2013, 85, 8802-8808.

(27) Savorani, F.; Tomasi, G.; Engelsen, S. B. J. Magn. Reson. 2010, 202, 190-202.

(28) Harwood L.J ; Weselake J. R, ${ }^{1} \mathrm{H}$ NMR spectroscopy of fatty acids and their derivatives [Online] 2005, http://lipidlibrary.aocs.org/nmr/1NMRintr/index.htm (accessed Feb 26, 2015).

(29) Willker, W.; Leibfritz, D. Magn. Reson. Chem 1998, 36, S79-S84.

(30) Pulkkinen, M. O.; Nyman, S.; Hamalainen, M. M.; Mattinen, J. Gynecolo Obstet Invest 1998, $46,220-224$.

(31) Vu, T. N.; Laukens, K. Metabolites 2013, 3, 259-276.

(32) Alonso, A.; Rodriguez, M. A.; Vinaixa, M.; Tortosa, R.; Correig, X.; Julia, A.; Marsal, S. Anal. Chem 2014, 86, 1160-1169.

(33) Lewis, S. J.; Heaton, K. W. Scand. J Gastro. 1997, 32, 920-924 